\title{
CONTRIBUIÇÃO PARA O ESTUDO DOS MECANISMOS DE TRANSMISSÃO DO AGENTE ETIOLÓGICO DA DOENÇA DE CHAGAS
}

\author{
Rosa Domingues Ribeiro * \\ Terezinha Aparecida Rissato e Garcia * \\ Walter Chinelatto Bonomo*
}

\begin{abstract}
RIBEIRO, R.D. et al. Contribuição para o estudo dos mecanismos de transmissão do agente etiológico da doença de Chagas. Rev.Saúde públ., S. Paulo, $21: 51-4,1987$.
\end{abstract}

RESUMO: Foram capturados no Município de Ribeirão Preto, SP, Brasil, exemplares de gambá, Didelphis albiventris. Na medida em que os exemplares chegavam ao laboratório foram submetidos a exames de sangue a fresco, hemoculturas e xenodiagnósticos, com o propósito de descartar a hipótese de infecção natural. Em cativeiro os animais passaram a ter, como parte de sua alimentação, camundongos parasitados pela cepa Bolívia do Tripanosome cruzi ou exemplares de triatomíneos comprovadamente infectados pela mesma cepa do parasita. Vinte e cinco dias após a última refeição, foram realizados xenodiagnósticos nos animais em experimentaçāo, cujo índice de in fecção nos animais que ingeriram camundongos infectados foi de $60,0 \%$ e naqueles que ingeriram triatomíneos foi de $83,3 \%$. Os resultados revelaram que os gambás apresentaram altos índices de infecção, mostrando a importância da via oral como porta de entrada do $T$. cruzi, bem como a importância do $D$. albiventris como reservatório do parasita nos focos naturais de infecção e elo de ligação entre o ambiente silvestre e o domicílio.

UNITERMOS: Trypamosoma cruzi. Didelphis, parasitologia. Camundongos, parasitologia. Triatomíneos, parasitologia. Vetores de doenças.

\section{INTRODUÇÃO}

Sendo a mucosa porta de entrada eficiente do Trypanosoma cruzi, é de se esperar que a simples ingestão de triatomíneos infectados ou a ingestão de alimentos recentemente contaminados com tripomastigotas metaciclicos, contidos no intestino posterior dos insetos, seja importante mecanismo de transmissão do parasita, principalmente entre animais insetivoros e onívoros. Esta hipótese não tem sido muito testada, mas há na literatura observações que vêm confirmá-la.

Parece que a primeira referência à transmissão do T.cruzi por ingestão de insetos infectados se deve a Dias $^{2}$ (1933) que, em laboratório, observou tatus devorarem exemplares de Panstrongylus megistus. $O$ autor entendeu que esse seria um mecanismo de transmissão freqüente entre animais silvestres, sendo com muita probabilidade o que acontece com tatus e macacos. Logo depois, Dias ${ }^{3}$ (1935) confirma a possibilidade de transmissão oral por ingestão de triatomíneos também entre animais domésticos como o gato, havendo observado xenodiagnóstico positivo em dois animais que anteriormente se alimentaram com barbeiros.

Posteriormente, Talice ${ }^{10}$ (1944); Torrico $^{11}$ (1950); Mayer $^{7}$ (1961) e Dias - Ungria ${ }^{5}$ (1965) confirmaram a possibilidade de transmissão do T.cruzi. contido em fezes de triatomineos, pela via oral.
Por outro lado, a transmissão do parasita por esta via, mediante a ingestão de tripomastigotas sangüineos, foi observada pela primeira vez por Mayer e Rocha Lima ${ }^{8}$ (1914) que, colocando gotas de sangue infectado sobre a mucosa bucal de camundongos, conseguiram resultados positivos. Nattan-Larrier ${ }^{9}$ (1921) obteve a infecção de dois terços dos camundongos que ingeriram sangue contendo tripomastigotas.

A possibilidade de transmissão do T.cruzi mediante a ingestão de animais infectados e, portanto, contendo tripomastigotas sangüíneos e amastigotas tissulares, foi demonstrada por Dias ${ }^{4}$ (1940), em gato adulto alimentado com camundongos infecta. dos.

Barretto e col. ${ }^{1}$ (1978) estudaram a possibilidade de infecção de vários mamíferos por via oral, mediante a ingestão, quer de triatomíneos infectados quer de animais de laboratório experimentalmente infectados pelo T.cnuzi. Jansen e Deane ${ }^{6}$ (1985) descrevem a in feç̧ão de camundongos pelo parasita contido nas glândulas anais de gambás, Didelphis marsupialis, pela ingestão de alimentos contamina. dos com esse material.

Como tais experiências revelaram que a via oral é um mecanismo eficiente de infeç̧ão do hospedeiro

* Departamento de Ciências da Saúde da Faculdade de Ciências Farmacêuticas de Ribeirão Preto da Universidade de São Paulo - Av. do Café $s / n$ ? - 14100 - Ribeirão Preto, SP - Brasil. 
RIBEIRO, R.D. et al. Contribuição para o estudo dos mecanismos de transmissão do agente etiológico da doença de Chagas. Rev. Saúde públ., S. Paulo, $21: 51-4,1987$.

vertebrado, resolvemos ampliar aquelas experiências e dar publicidade aos resultados de nossas investiga. ções.

\section{MATERIAL E METODOS}

Foram capturados, no Município de Ribeirão Preto, cinco exemplares machos e três exemplares fêmeas do gambá, D. albiventris, sendo que uma das fêmeas apresentava, no interior de sua bolsa marsupial, três filhotes.

Foram efetuados exames de sangue a fresco, hemoculturas e xenodiagnósticos, na medida em que os animais chegavam ao laboratório e ram mantidos em cativeiro. $O$ propósito de tal realização foi o de afastar a hipótese de infecção natural. Para isso, os exames foram efetuados com exemplares de triatomíneos, em número de dez por animal e durante quatro semanas. As hemoculturas também foram realizadas em série de quatro, semeando-se sangue colhido por capilaridade da cauda do animal, em cinco tubos de vidro de pequeno diâmetro e estéreis contendo meio liquido de Warren. O material assim obtido, foi mantido a $28^{\circ} \mathrm{C}$ e examinado após 15,30 e 45 dias.

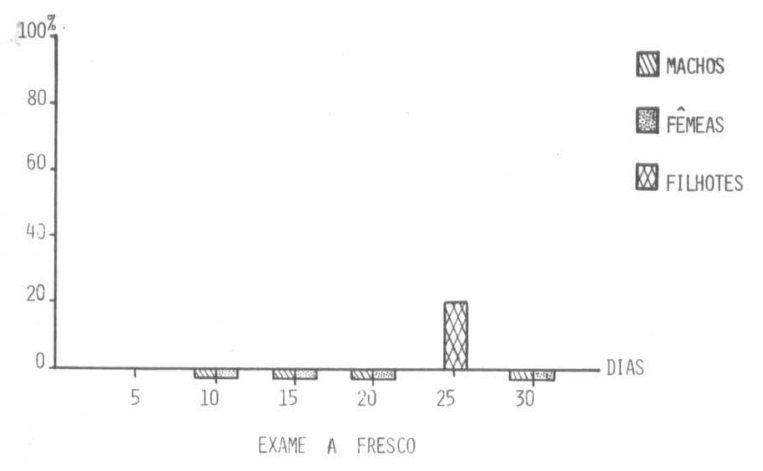

Após a última realização da hemocultura e xenodiagnóstico, os gambás passaram a ter como parte de sua alimentação, camundongos parasitados pela cepa Bolívia do T.cruzi, ou exemplares de triatomíneos comprovadamente infectados pela mesma cepa do parasita. Convém ressaltar que, dependendo do caso, o animal comia com certa avidez o que the era oferecido. Assim, por três vezes, os marsupiais tiveram à disposição os camundongos $\mathrm{e}$ os insetos infectados, para ingestão.

Os gambás foram submetidos a uma série de exames de sangue a fresco e no 25 \% dia após a última refeição, ao xenodiagnóstico utilizando-se exemplares de triatomíneos pertencentes às espécies Triatoma infestans e Rhodnüs neglectus que foram examinados, por maceração do tubo digestivo, trinta dias após a realização do xenodiagnóstico.

\section{RESULTADOS E DISCUSSÃO}

Os resultados obtidos com os animais que tive. ram como parte de sua alimentação camundongos ou triatomíneos infectados pela cepa Bolívia do $T$. cruzi, são apresentados nas Figuras 1 e 2.

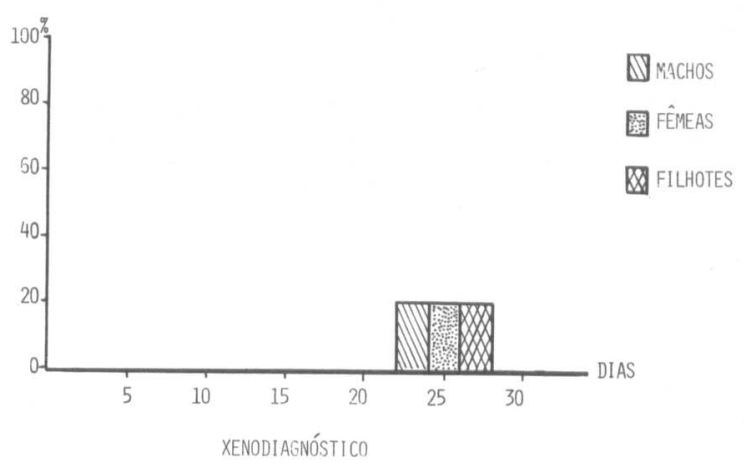

Fig. 1 - Iñdice de infeç̧ão de gambás, pela ingestão de camundongos, revelauos por meio do exame de sangue a frescoe do xenodiagnóstico.
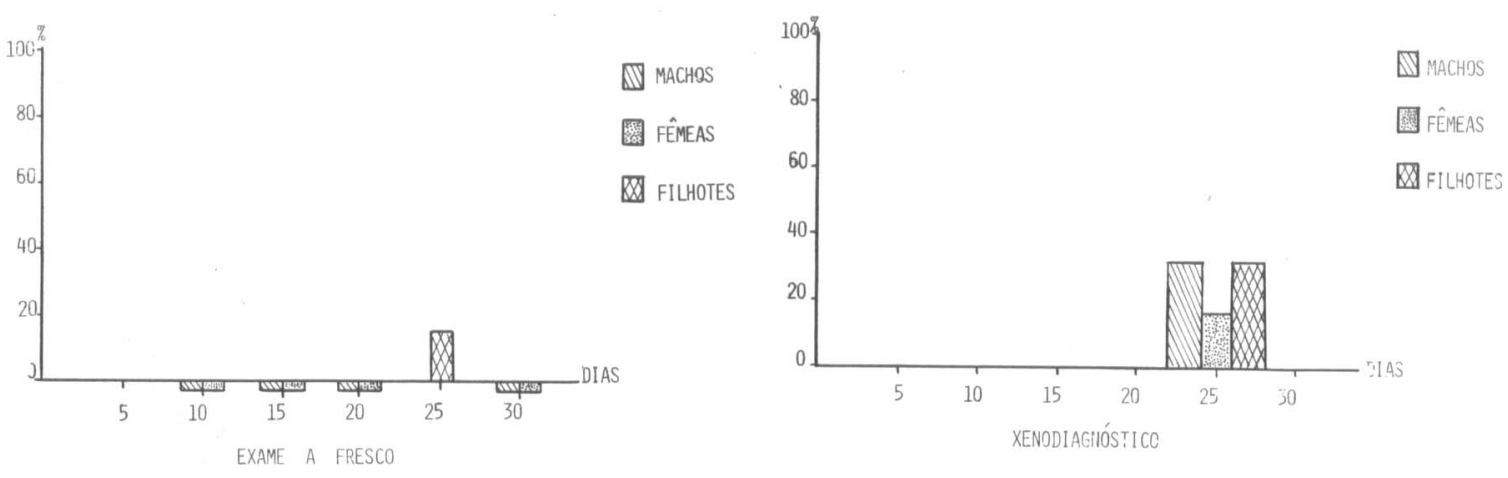

rig. 2 - Indice de infeç̧a de gambás, pela ingestão de triatomíneos, revelados por meio do exame de sangue a fresco e do xenodiagnóstico. 
RIBEIRO, R.D. et al. Contribuição para o estudo dos mecanismıs de transmissão do agente etiológico da doença de Chagas, Rev. Saúde públ., S. Paulo, 21: 51-4, 1987.

A análise dos resultados revela que no primeiro grupo, ou seja, aquele em que os gambás limpos ingeriram camundongos infectados, constatamos $60,0 \%$ de infecção. Convém assinalar que os gambás foram examinados a partir de dez dias após a última refeição, a cada três dias, através do exame de sangue a fresco. Somente o filhote de gambá revelou-se positivo por este método, enquanto os machos e fêmeas mostraram-se negativos. Por outro lado, foi através do xenodiagnóstico realizado no 25 \% dia após a alimentação que constatamos $60,0 \%$ de infeç̧ão.

No segundo grupo, isto é, o dos animais que ingeriram triatomíneos infectados, o índice de infecção foi de $83,3 \%$. Também neste grupo os gambás adultos apresentaram resultados negativos através do exame de sangue a fresco enquanto um dos filhotes mostrou-se positivo. Através do xenodiagnóstico a infecção revelou-se em $83,3 \%$ dos gambás.

Embora o número de animais em experimentação não seja grande, perfazendo um total de 11 , consideramos esses resultados de grande importância pois, nos focos naturais da Tripanosomíase Americana, os gambás poderiam adquirir a in fecção pela via oral porque esses marsupiais são onivoros e em suas mi- grações ao ingerir pequenos roedores ou triatomíneos infectados, se transformariam em portadores da parasitose.

Realmente, tal fato é comumente observado entre os gambás que mudam muito de local à procura de alimentos, principalmente na zona rural, onde andam do foco silvestre para o domicilio e vice-versa podendo eventualmente, ao encontrar condições favoráveis, estabelecer um novo foco de infecçao.

Assim, achamos válida a presente contribuição, pois amplia os dados sobre a possibilidade de transmissão do T.cruzi, tendo como porta de entrada a via oral ou digestiva entre os marsupiais, isto é, através da ingestão de triatomíneos e mamíferos infectados, além de destacar a importância do D.albiventris dentro da epidemiologia da Doença de Chagas como elo de ligação entre o ambiente silvestre e o domicílio.

\section{AGRADECIMENTOS}

Ao Sr. Paulo Regis Alonso Toldo, pela colaboração técnica especializada.

RIBEIRO, R.D. et al. [A contribution to the study of the mechanisms of transmission of the etiological agent of "Chagas" disease]. Rev. Saúde públ., S. Paulo, 21 : 51-4, 1987.

ABSTRACT: The infection of several opossums Didelphis albiventris, male, female and young, by oral means by feeding them either on infected triatomines or on mice experimentally infected by Tripanosoma cruz $i$, is studied. After feeding uncontaminated opossums on carcasses or living specimens of baby mice, infected with the Bolivian strain of $T$.cruzi, a $60.0 \%$ infection index was obtained on xenodiagnoses. On the other hand, after feeding uncontaminated opossums on infected triatomines, an $83.3 \%$ index was obtained on xenodiagnoses. These results indicate that the feeding on infected mammals, as well ds the ingestion of infected triatomines by omnivorous animals gives high in fection indices and demonstrates the importance of the oral route as the means of access of $T$. cruzi. The also show the impoilance of opossums as reservoirs of the parasite in the natural focci of infection and as carriers of $T$. cruzi to the domicile because of their migratory habits.

UNITERMS: Trypanosoma cruzi. Opossums, parasitology. Mice, parasitology. Triatomidae, parasitology. Disease vectors.

\section{REFERENCIAS BIBLIOGRAFICAS}

1. BARRETTO, M.P.; RIBEIRO, R.D. \& BELDA NETO, F.M. Estudos sobre reservatórios e vectores silvestres do Trypanosome cruzi. LXVIII: In fecção de mamíferos pela via oral. Rev.bras.Biol., $38: 455-469$, 1978.

2. DIAS, E. Estudos sobre o Schizotrypanum cruzi. Rio de Janeiro, 1933. [Tese de Doutorado - Fac. Med. Univ. Rio de Janeiro].

3. DIAS, I. Xenodiagnóstico e algumas verificações epidemiológicas na moléstia de Chagas. In: Reunião da Sociedade de Patologia Regional, 9. Buenos Aires, 1935, v. 1. pg. 89-119.
4. DIAS, E. Transmissâo do Schizotrypanum cruzi entre vertebrados por via digestiva. Brasil méd., $54: 775$, 1940.

5. DIAZ-UNGRIA, C. Transmission del Trypanosoma cruzi en los vertebrados. Rev, iberica Parasitol., 25 : 1-44, 1965.

6. JANSEN, A.M. \& DEANE, M.P. Trypanosome cruzi infection of mice by ingestion of food contaminated with material of the anal gland of the opossum $D i$ delphis marsupialis. In: Reunião sobre Pesquisa Básica em Doenças de Chagas, 12. Caxambu, MG, 1985. p. 39. 
RIBEIRO, R.D. et al. Contribuição para o estudo dos mecanismos de transmissão do agente etiológico da doença de Chagas, Rev. Saude públ., S. Paulo, 21 : 51 -4, 1987.

7. MAYER, H.F. In fección experimental con Trypano. soma cruzi por via digestiva. An. Inst.Med.Regional, $5: 43-8,1961$.

8. MAYER, M. \& ROCHA LIMA, H. Zum verhalten von Schyzotrypanum cruzi in warmblütern und Arthropoden. Arch.Schiffs. Tropen-Hyg., 18: 101-36, 1914.

9. NATTAN-LARRIER, L. Infeccions à trypanosomes et voies de pénétration des virus. Bull. Soc. Pathol. exot., $14: 537-42,1921$.
10. TALICE, R.V. Enfermedades parasitarias del hombre $y$ parásitos de interés médico. Montevideo, Monteverde Ed., 1944, v. 1.

11. TORRICO, R.A. Conocimientos actuales sobre la enfermedad de Chagas en Bolivia. Bol.Ofic. sanit. Panam., 29: 827-41, 1950.

Recebido para publicação em 04/08/1986

Reapresentado em 05/12/1986

Aprovado para publicaç̄̄o em 05/12/1986 